\title{
Creating, Sustaining and Realising the Value of a Faculty-wide Community of Teaching Practice
}

\author{
Michelle Honey ${ }^{1}$, Trudi Aspden ${ }^{2}$, Anuj Bhargava ${ }^{3}$, Louise Carrucan-Wood ${ }^{1}$, Angela Tsai ${ }^{4}$, Jenny Sim $^{4}$ \\ ${ }^{1}$ School of Nursing, The University of Auckland, Grafton Campus, 85 Park Road, Auckland, New Zealand; \\ m.honey@auckland.ac.nz; 1.carrucan-wood@auckland.ac.nz \\ ${ }^{2}$ School of Pharmacy, The University of Auckland, Grafton Campus, 85 Park Road, Auckland, New Zealand; \\ t.aspden@auckland.ac.nz
}

${ }^{3}$ Dept of Physiology, School of Medical Sciences, The University of Auckland, Grafton Campus, 85 Park Road, Auckland, New Zealand; a.bhargava@auckland.ac.nz

${ }^{4}$ Dept of Anatomy and Medical Imaging, School of Medical Sciences, The University of Auckland, Grafton Campus, 85

Park Road, Auckland, New Zealand; a.tsai@ auckland.ac.nz, j.sim@auckland.ac.nz

*Corresponding author - Michelle Honey; m.honey@auckland.ac.nz; 1.carrucan-wood@ auckland.ac.nz

Received 04 March 2019;

Accepted 16 March 2019;

Published 24 March 2019;

\begin{abstract}
Communities of practice are frequently described and discussed in academic literature and within education. They are depicted as groups of people with a shared interest coming together and in a higher education setting this shared interest relates to the practice of teaching and learning. The establishment of a cross-discipline faculty-wide community of practice to support educators in higher education is novel. This paper describes the establishment of a community of practice within one university faculty uniting educators across multiple disciplines within the Faculty. Data spanning thirty months since the inception of a teaching and learning community are presented. The findings illustrate a growing community of practice, along with perceived benefits and future directions. The creation of an interprofessional faculty-wide community of practice illustrates how educators can be drawn together because of their common passion for teaching and learning and a mutual concern of how to maximise student learning.
\end{abstract}

Keywords: university, faculty, social learning, community of practice, interprofessional, New Zealand.

\section{Introduction}

A community of practice $(\mathrm{CoP})$ has been defined as 'groups of people who share a concern or a passion for something they do and learn how to do it better as they interact regularly ${ }^{[1]}$. In terms of faculty members who have a teaching component to their role, this group of people includes educators across a range of disciplines from one faculty in one university. The common concern or passion (domain of the $\mathrm{CoP}$ ) they share is their teaching practice. Establishing a faculty-wide forum for those with a similar interest in teaching and the promotion of student learning to collaborate was the aim when a small group provided leadership to enable interested faculty members to share their experiences and learn from the experience of others. This paper reports on progress three years after the initial conception of a faculty teaching and learning group. It illustrates how the community of practice developed, and describes the benefits thus far and potential future directions.

\section{Learning Community}

www.ijirms.in
Building on the social learning aspects of Vygotsky's 1962 work, Lave and Wenger contend that learning is a function of the activity, context and culture in which it is situated. The principles behind their work are based on the notion that learning requires social interaction and collaboration. The social interaction of learners is a critical component of a community of practice, which exemplifies certain beliefs and behaviours ${ }^{[2,3]}$.

Wenger suggests there is both an individual and collective aspect that creates a social history of learning among participants in a group $^{[4]}$. This gives rise to a shared understanding for the group on:

- What matters, what the enterprise of the community is, and how it gives rise to a perspective on the world.

- Having the opportunity (and feeling empowered) to engage productively with others in the community.

- Appropriate use of the repertoire of resources accumulated by the community through its history of learning. 
Furthermore, Wenger suggests that over time an 'informal and dynamic social structure among the participants' can develop, and this is what a community of practice is ${ }^{[4]}$.

A sense of belonging has been suggested to be a feature of a community of practice ${ }^{[5,6]}$. Yet activity and participation within the community is not homogenous across members. Some members are more active at specific times, and for others reading or listening to others is sufficient and less active participation is all they want. Lave and Wenger term this less active involvement as 'peripheral participation' but suggest that this is just as valid as more active involvement maintaining that this level of engagement may still provide a sense of belonging ${ }^{[3]}$.

\section{Context}

The university which is the context for this article is a leading university in Australasia. It comprises eight faculties and a number of research centres and institutes. The focus here is on the Faculty of Medical and Health Sciences (FMHS), one faculty that encompasses six schools; medical sciences, medicine, nursing, optometry and vision science, pharmacy and population health, and numerous health-related institutes, departments and sections including Te Kupenga Hauora Māori, biomedical imaging and nutrition. This faculty has approximately 1,500 staff with nearly 400 being employed in roles that include a teaching component. While the university has a student body of nearly 42,000 , current enrolment figures for the FMHS indicate there are approximately 6,300 students across pre-degree, undergraduate and postgraduate levels $^{[7]}$.

The university has a teaching and learning strategy which is informed by the broader University Strategic Plan (2013-2020), a Charter and the Graduate Profile ${ }^{[8]}$. The teaching and learning strategy recognises that 'the ability to share and grow ideas, reflect on practice and evolve the learning environment' is key to successful teaching practice ${ }^{[8]}$. Two themes of the teaching and learning strategy are particularly relevant in the context of this paper: Enhancing teaching capability and acknowledging teaching leadership and building a leadership culture around pedagogical research and practice. However, such strategies are overarching, 'top down' and may be limited in their relevance to individual educators who are usually busy with their teaching schedules and marking. In an attempt to support the wider university strategies, yet aiming to provide a 'bottom up', egalitarian approach, a faculty wide teaching \& learning initiative was introduced.

\section{Method}

This paper presents a descriptive account of the development of a faculty wide Teaching and Learning Community (TLC) and provides a longitudinal view from the TLC inception in 2016 through to mid-2018. The aim from the outset was to foster a community of learning (based on the work of Wenger, McDermott and Synder ${ }^{[9]}$ ), where interested staff members could come together on a regular basis to share their professional learning, support one another in teaching initiatives and contribute towards a positive culture of learning and teaching within the FMHS.

\subsection{Background}

In recognition of the absence of an informal network at the ground level to support learning and teaching, a staff member (author JS) applied for the 2016 FMHS Learning and Teaching Fellowship with the aim of developing a community of practice. The purpose of the teaching community was to form a critical mass at the ground level to foster, promote and share learning and teaching practices in a safe and supportive environment. It was the intention that this informal network or Teaching \& Learning Community (TLC) would serve as a forum or exchange that would lead to interdisciplinary collaborations of innovative teaching practices within and beyond the FMHS. Together with the 2015 and 2014 Fellows (AT and TA), the trio started the TLC in January 2016.

To achieve this goal of creating a TLC, initial plans were for a series of fortnightly informal gatherings of any interested educators. The aim of these sessions was to share and unpack teaching problems and explore possibilities, exchange ideas about all aspects of learning and teaching so all could learn from the experiences of others and create new knowledge and practice in the faculty - all in a friendly and supportive environment. These gatherings were planned as short, half hourly sessions run specifically to meet attendees' needs. Hence, whether an educator was new to teaching or experienced it was anticipated there would always be benefits in attending sessions and being a part of an informal network. Sessions aimed to include space for getting to know and chatting with like-minded colleagues, working through teaching challenges to find solutions or becoming aware of novel teaching techniques to pilot in their classes, or establishing potential mentor/mentee relationships.

\subsection{Data Sources}

Data sources were meeting schedules, records of attendance, an anonymous survey and the online repository of resources. The survey was distributed at the end of 2016 using Survey Monkey and consisted of two questions:

1. Why do you attend the TLC sessions?

2. How many times have you accessed the resources on the online repository?

Members also had the opportunity to provide additional commentary if they wished. The authors have all facilitated and participated in TLC meetings and reflections on the evolution of the TLC are included.

\section{Findings}

\subsection{Promoting attendance at gatherings}

To encourage educators to attend, the timing of the gatherings were scheduled to immediately precede FMHS staff meetings. The gatherings were promoted via the Faculty's email lists and a notice was included in the weekly Dean's newsletter. Once more established, gatherings have been promoted via the Faculty's teaching email list and through communication via the University learning management system (LMS).

\subsection{Themes and topics of gatherings}

To provide an overview of the topics covered, six overarching themes were identified where each theme consisted of two to seven gatherings offering insights around a theme (Table 1: Examples of themes and associated gathering topics).

The first meeting, which had 20 attendees, was general and focused on establishing the way the group would function and what themes and topics were of interest. The 2016 themes were often related to the Faculty and University agenda. For instance, the commencement of the TLC coincided with the introduction of the 
university-wide new LMS. As the TLC was designed with the aim of the meeting the needs of the members, the introduction of a new LMS was a noted topic occurring five times (27\% of gatherings) in 2016. The increased awareness and reputation of the TLC from 2016 to the present has made it easier to attract speakers. For example, the first TLC meeting in 2018 included an update on strategic direction by the Associate Dean (Academic).

\subsection{Members}

There is no formal membership of the TLC, rather people can attend any gathering they wish to and have the option of joining a TLC 'Class' created on the university LMS. From the first meeting of 20 , there are now nearly one third $(n=119 ; 29.75 \%)$ of all faculty educators who have joined the LMS TLC 'Class'. There may also be others who feel they are part of the TLC who attend gatherings, but have chosen not to join the LMS 'Class'.

Table 1: Examples of themes and associated gathering topics

\begin{tabular}{|c|c|}
\hline Theme & Topics \\
\hline $\begin{array}{l}\text { Learning } \\
\text { Management } \\
\text { System }\end{array}$ & $\begin{array}{ll}\text { - } & \text { Tricks and hacks } \\
\text { - } & \text { Assessment } \\
\text { - } & \text { Setting up and use of quizzes } \\
\text { - } & \text { Linking to a reading list (in partnership } \\
& \text { with staff from the library) }\end{array}$ \\
\hline $\begin{array}{l}\text { Organisational } \\
\text { Support }\end{array}$ & $\begin{array}{ll} & \text { Counselling and health services } \\
\text { - } & \text { Maori and Pacific student support }\end{array}$ \\
\hline $\begin{array}{l}\text { Professional } \\
\text { Development }\end{array}$ & 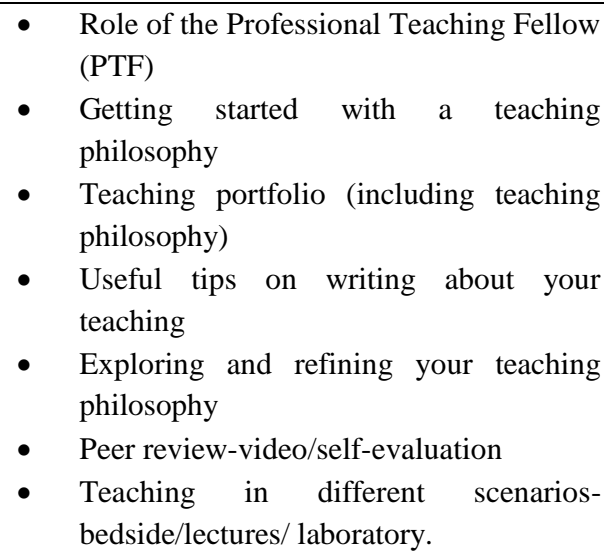 \\
\hline $\begin{array}{l}\text { Scholarship of } \\
\text { Teaching }\end{array}$ & $\begin{array}{l}\text { - Thinking of applying for a Learning and } \\
\text { Teaching Fellowship? } \\
\text { - Journal club } \\
\text { - TED talks as a resource } \\
\text { - Teaching awards - what there are and } \\
\text { how to apply? }\end{array}$ \\
\hline $\begin{array}{l}\text { Curriculum } \\
\text { Design }\end{array}$ & $\begin{array}{l}\text { - } \text { Conceptual frameworks } \\
\text { - } \quad \text { Graduate profile and embedding it in the } \\
\text { - } \quad \text { Curriculum } \\
\text { - } \quad \text { Assessment properties and support }\end{array}$ \\
\hline $\begin{array}{l}\text { Student } \\
\text { Feedback }\end{array}$ & 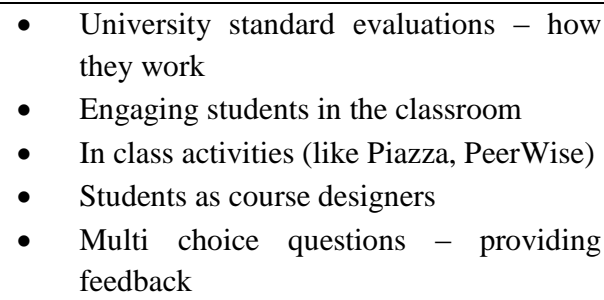 \\
\hline
\end{tabular}

\subsection{Attendance}

Attendance has ranged from 5 to 21 educators, with each session averaging approximately 12 attendees. There was a slight increase in the average number of attendees at gatherings in 2018. A summary is provided in Figure 1.

\section{- 2016}

65 staff attended at least one session.

Total number of attendees at all sessions: 206

Average number of attendees per session: 12

- 2017

112 staff attended at least one session.

Total number of attendees at all sessions: 173

Average number of attendees per session: 12

- 2018 (to 30 June)

69 staff attended at least one session.

Total number of attendees at all sessions: 118

Average number of attendees per session: 17

\section{Figure 1: Summary of attendance}

Excluding the inaugural meeting, where refreshments were provided and the behavioural expectations and directions of the group were discussed and agreed upon, the most popular and wellattended sessions were three sessions focusing on writing about teaching: Useful tips on writing about your teaching; Getting started with a teaching philosophy and Exploring and refining your teaching philosophy.

\subsection{Survey}

To get an indication of whether to continue the TLC members were anonymously surveyed at the end of the first year, 2016, using an online questionnaire administered via Survey Monkey (Figure 2). Free text responses expressed in the survey and from unsolicited comments during meetings indicated there was a direct impact on some educators' practices and that attending gatherings triggered some people to question some of their assumptions and practices.

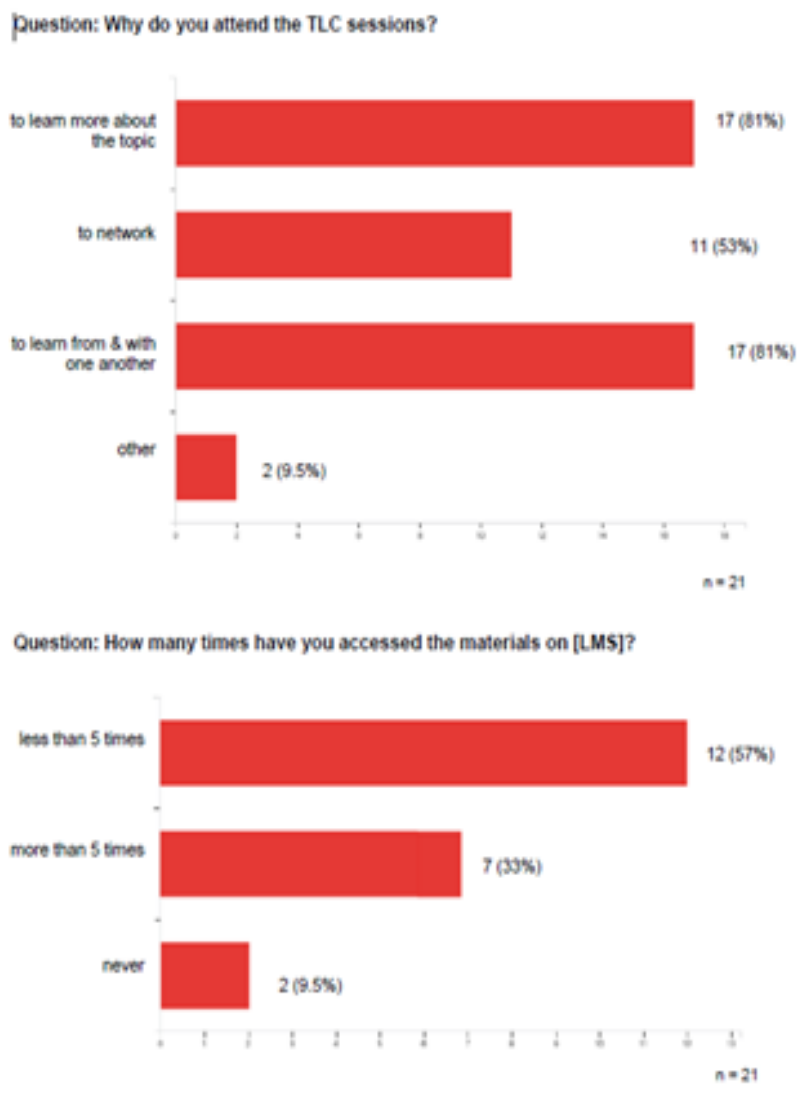

Figure 2: Survey feedback from members in 2016 
In addition, 20 out of 21 people (95\%) thought that the TLC sessions should continue in 2017. Members were also able to provide open-ended feedback and this included:

"It is great to have a meeting 'space' for the community of people in the Faculty interested in teaching and learning. The formal/informal balance is about right and it accommodates the comings and goings of people in a non-threatening but academic environment."

"As equally important for me is to encourage a network of 'learners' who can share successes, failures, ideas, risks in a supportive community of like-minded people so a big part of me attending too has been to support the organising committee who I respect and to further the network of like-minded individuals as we get to know each other more."

\subsection{Online repository- LMS TLC 'Class'}

The LMS was used to create a TLC 'Class' from the outset, with two key notions behind its use. Firstly, the new LMS had just been introduced and it provided a way for educators to use the LMS for non-teaching purposes thereby enabling users to become more familiar with the LMS environment. Secondly, it was ideal to provide a cross-faculty repository of information and a means for all educators to communicate and collaborate. As any resources uploaded were online, easy access was possible for all educators (Table 2).

Table 2: Online TLC resources

\begin{tabular}{|c|c|l|}
\hline Year & $\begin{array}{c}\text { Number of } \\
\text { resources }\end{array}$ & Format of resources \\
\hline 2016 & 33 & $\begin{array}{l}\text { PowerPoint presentations, } \\
\text { meeting notes, relevant } \\
\text { documents / articles }\end{array}$ \\
\hline 2017 & 35 & $\begin{array}{l}\text { PowerPoint presentations, } \\
\text { meeting notes, relevant } \\
\text { documents / articles }\end{array}$ \\
\hline $\begin{array}{c}\text { 2018 } \\
\text { (to 30 June) }\end{array}$ & 9 & $\begin{array}{l}\text { PowerPoint presentations, } \\
\text { meeting notes, relevant } \\
\text { documents / articles }\end{array}$ \\
\hline 2016-2018 & 16 & $\begin{array}{l}\text { Videos - either related to } \\
\text { gatherings or shared by } \\
\text { members }\end{array}$ \\
\hline
\end{tabular}

The nature of the gatherings determined the resources that might be provided. For example, a topic of 'Tips on writing about your teaching' had a PowerPoint, a relevant University document and examples provided by speakers or members. Alternatively, a panel session that included students sharing what they found effective to support their learning had no resources.

The majority ( $\mathrm{n}=105 ; 88 \%)$ of members have joined the LMS TLC 'Class'. Analysis of the LMS data indicates that use of the TLC 'Class' has increased over time. While for some aspects of the TLC 'Class' there appears to be minimal engagement there are also examples of those who have engaged more (Table 3). There was also evidence of some very active members: 18 members who have accessed information more than five times and seven members have accessed information 10 or more times.
Table 3: Most common use of the LMS by the TLC

\begin{tabular}{|l|l|c|}
\hline \multicolumn{1}{|c|}{ LMS Section } & \multicolumn{1}{|c|}{ Use } & $\begin{array}{c}\text { Number of } \\
\text { times accessed }\end{array}$ \\
\hline People & $\begin{array}{l}\text { Check who else is a } \\
\text { member }\end{array}$ & 26 \\
\hline Modules & See available topics & 42 \\
\hline Resources & Lists available resources & 30 \\
\hline Announcements & $\begin{array}{l}\text { Information on upcoming } \\
\text { gatherings }\end{array}$ & 20 \\
\hline
\end{tabular}

In addition to the above uses, three online discussions allowed members to collaborate outside of gatherings, though these were not very successful as noted by minimal activity. The exception to this was one discussion that followed a gathering focusing on changes to student evaluation processes, which garnered many posts and a vibrant debate ensued. These discussions were not moderated and were led by members so the level of activity indicates topics of interest from members.

\subsection{Collective leadership}

The TLC is now an established feature with the FMHS community. A decision was taken not to assess the success of the 2016 TLC simply by the frequency of the TLC meetings and the number of attendees. Rather, the criteria of success was determined by whether there was sufficient ground level support to keep the TLC going in 2017 and beyond. In a survey conducted in September 2016, members expressed the desire to continue the TLC into 2017. However, there was an acute awareness that facilitating and leading the TLC falling on the small initial group for the entire year was too onerous a task. This was compounded by the fact that many staff members assume dual roles within the faculty of teaching and clinical work. Thus, to ensure sustainability, the 2016 TLC members agreed a more manageable strategy was to adopt a collective leadership approach by dividing the TLC leadership team into three groups, with each group consisting of four to five members responsible for a four-month programme. This format of distributed leadership was deemed to be a success and the TLC leadership format was continued in 2018.

\section{Discussion}

Wenger considers a community of practice to have three crucial characteristics: A domain, community, and practice ${ }^{[1]}$. Each of these will now be considered in relation to the findings presented above thereby demonstrating that a community of practice was established.

\subsection{Domain}

The first characteristic Wenger considers essential for a community of practice is an identity defined by a shared domain of interest ${ }^{[1]}$. This is shown by a steady increase in numbers attending gatherings and in that just under a third of all educators within the faculty have joined the LMS TLC 'Class'. Additionally, peripheral participation, which Lave and Wenger describe as those who are less actively involved, may be occurring within the group with some educators attending gatherings but not subscribing to the TLC 'Class', or alternatively some educators may not attend gatherings but may access resources ${ }^{[3]}$.

\subsection{Community}

Secondly, the community and having a sense of being part of a community may be present, even among those who peripherally participate. The steady growth of members since the group was 
established is an indication of a community developing. This is further supported by the members engaging in activities and discussions, and in the way members help each other and share information. In the brief survey after the first year, one member described their reason for attending the TLC as part of how to 'get to know each other more'.

This sense of community is further supported by Vescio, Ross and Adam's review of teaching communities that highlighted the organic growth of collaborative efforts and development of strategies that open up teaching practices to encourage sharing, reflecting, and may result in an attempt to make changes to existing teaching practices ${ }^{[10]}$. An excellent example of this sense of being part of a community arising from this work is the way members engaged within the group by offering to take up leadership roles, organising and facilitating gatherings. A study in the United Kingdom found healthcare professionals are likely to hold positive views about shared leadership, which this paper supports ${ }^{[11]}$. Additionally, the 2017 study by Forsyth and Mason identified no differences between healthcare professions in their beliefs about shared leadership ${ }^{[11]}$. The current paper echoes this finding that the leaders in the TLC came from varied roles and professional backgrounds.

Gatherings and the discussions, both in person and on-line helped to build relationships so members could learn from each other. While Wenger ${ }^{[1]}$ did not suggest that using a university LMS creates a community of practice, it was evident from members' access and use of resources that the LMS serves as a useful platform for information exchange and shared practice. Staff members who were unable to attend the TLC gatherings, either due to teaching commitments or clinical work, were able to access the information and still be part of the TLC.

\subsection{Practice}

Finally practice, in this instance teaching practice, refers to the activity of all educators within the Faculty. The sharing of experiences and resources all related to teaching and learning. The discussions built into many of the gatherings were key to creating opportunities to share both the successes and issues that members faced in terms of their teaching practice. A review of 11 studies on professional learning communities found that these types of activities were a feature of successful collaborations which encouraged changes in teaching culture ${ }^{[10]}$. The themes and topics of the TLC gatherings reflect common concerns about aspects of teaching practices, from the new LMS, organisational support available for students, to student feedback.

\subsection{The impact of an established community of practice}

The impacts of an established and thriving TLC and community of practice have been multiple. The benefits of a community of practice have been described by Hollinshead, Stirling, Kerr and Massey as providing a forum for sharing knowledge, learning and innovation, and also providing a vehicle for collaborative problemsolving, all of which have been evident in the examples presented in this paper $^{[12]}$.

Examples of the impact of the TLC include having the ongoing TLC 'Class' and the repository of resources on the LMS has provided access to information and files beyond the year of initial presentation. While planning for the commencement of a new programme, one of the authors (JS) accessed a 2016 PowerPoint presentation on curriculum mapping during a departmental 2017 staff meeting to inform the team on curriculum mapping. Another author (AT) also reported that when teaching colleagues voiced concerns about the institution's transition from paper-based student evaluation teaching to an online only tool and its impact on participation rates and the prescribed question set not being fit-forpurpose for different teaching contexts, she was able to refer colleagues to a TLC session whereby she shared resources and solutions to these issues. Additionally, the gatherings have provided a venue for meeting other educators and this has helped getting to know others in the faculty and increased collegiality. The collective leadership approach adopted has provided an opportunity for a number of members, who hold fractional appointments for a number of reasons, e.g. clinical roles, to demonstrate and develop leadership at the faculty level. In the academic environment, evidence of providing leadership can be helpful for an individual's annual performance reviews.

A further example of the impact of the TLC has been as a voice on teaching matters and as a lobby group, specifically for professional teaching fellows (PTFs). The 2016 TLC leadership team tabled a report to the Faculty Education Committee summarising the 2016 TLC journey, including issues that were raised by members during the gatherings. One of the issues raised included members identifying the lack of funding support for PTFs. Successful lobbying has resulted in a teacher development fund for FMHS professional teaching fellows (PTFs) which was launched by the Associate Dean (Academic) in May 2018. This is consistent with some of the functions of communities of practice proposed by Wenger and Wenger-Treyner namely problem solving and the development of a 'collective and strategic voice ${ }^{,[13]}$.

\subsection{Limitations}

The TLC is now in its fourth year of operation. It is anticipated that there is now sufficient momentum at the ground level within the faculty that the TLC is likely to continue in the future. Despite its success, there is a lack of empirical evidence as to how the TLC has influenced or impacted members of the teaching community. Further research is therefore required to investigate the impact of the TLC at an individual member level and at the wider faculty level.

\section{Conclusion}

The success of the TLC is evidenced by its continuity beyond 2016. Drawn together by a common passion for teaching and learning, we come together to share, encourage and to support one another in the pursuit of teaching excellence. This paper is one of the many benefits and provides evidence of how a shared vision of promoting teaching excellence can cross interdisciplinary boundaries and motivate faculty staff to work together towards a common goal.

\section{References}

[1] E. Wenger, "Communities of practice: A brief introduction", in, University of Oregon, STEP Leadership Workshop, 2011, pp. 1-7. Available: http://hdl.handle.net/1794/11736

[2] L.S. Vygotsky, Thought and language, MIT Press, Cambridge, MA, 1962.

[3] J. Lave and E. Wenger, Situated learning: Legitimate peripheral participation, Cambridge University Press, Cambridge, United Kingdom, 1991. 
[4] E. Wenger, Communities of practice and social learning systems: The career of a concept, in: Social learning systems and communities of practice, C. Blackmore, ed., Springer, London, pp. 179-198, 2010.

[5] E. Wenger, Communities of practice: Learning, meaning, and identity, Cambridge University Press, Cambridge, United Kingdom, 1998.

[6] E. Wenger, "Communities of practice and learning systems", Organization 7 (2), 225-246, 2000.

[7] University of Auckland. 2017. "Key Statistics 2016." Available:

https://cdn.auckland.ac.nz/assets/auckland/about-us/ourranking-and-reputation/key-statistics-2016-final.pdf.

[8] University of Auckland. 2016. "Learning and Teaching Plan $2017 \quad-\quad$ 2019." $\quad$ Available: https://cdn.auckland.ac.nz/assets/auckland/staff/learningteaching/strategy-plans-qa/learning-and-teachingplans/LTP-2017-19-Approved-by-Council-Dec2016.pdf.

[9] E. Wenger, R. McDermott, and W.M. Snyder, Cultivating communities of practice: $A$ guide to managing knowledge, Harvard Business School Press, Boston, MA, 2002.

[10] V. Vescio, D. Ross, and A. Adams, "A review of research on the impact of professional learning communities on teaching practice and student learning", Teaching and Teacher Education 24(1), 80-91, 2008. Available: https://doi.org/10.1016/j.tate.2007.01.004.

[11] C. Forsyth and B. Mason, "Shared leadership and group identification in healthcare: The leadership beliefs of clinicians working in interprofessional teams, Journal of interprofessional care" 31(3), 291-299, 2017. Available: https://doi.org/10.1080/13561820.2017.1280005.
[12] J. Hollinshead, L. Stirling, P. Kerr, and D. Massey, "Developing a successful community of practice to improve service delivery", Journal of Health Visiting 3
(4), $1-6$,
2015.
Available https://doi.org/10.12968/johv.2015.3.4.226.

[13] E. Wenger and B. Wenger-Trayner, Communities of practice A brief introduction, 2015. Available from http://wenger-trayner.com/wpcontent/uploads/2015/04/07-Brief-introduction-tocommunities-of-practice.pdf in.

\section{Author Profile}

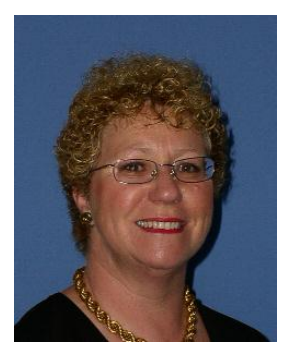

Michelle Honey Corresponding author for this paper is Doctor Michelle Honey, who is a nurse with 30 years experience; over half in nursing education. She currently works at the School of Nursing at the University of Auckland in New Zealand. Michelle has a long-standing interest in nursing informatics which has led to research in exploring how information technology can impact nursing and health care - from technology to support consumers, provision of health services utilizing technology and the use of technology for education. 